\title{
EFFECTS OF INTERACTION STRATEGIES ON STUDENTS' MUSIC LISTENING WITH A MOBILE APPLICATION
}

\author{
Yoomee Baek ${ }^{1}$ and Sunggi $\mathrm{Cho}^{2}$ \\ ${ }^{1}$ University of Hawaii at Manoa, Department of Music, 2411 Dole St. Honolulu, HI USA 96822 \\ ${ }^{2}$ Kongju National University, Department of Music Education, 56 Gongjudaehak-ro, Shinkwan-dong, Gongju, \\ Chungcheongnam-do, South Korea 32588
}

\begin{abstract}
The purpose of this study is to explore how three interaction strategies through mobile applications affect students' music listening. Data was collected from 225 high school students and analyzed using the ANCOVA procedure in the three domains of music listening: analytic, aesthetic and sensory. Research showed that the interaction with teachers was most influential in the analytic listening of the participants. Interaction with peers was most influential in aesthetic listening of the participants. Interaction with the application was most influential in sensory listening of the participants. Differences in students' satisfaction according to the three interactions through the mobile application are discussed. This study has implications on how interactions could be designed for students' music listening.
\end{abstract}

\section{KEYWORDS}

Music Listening, Mobile Application in Music Listening, Music Listening Strategies

\section{INTRODUCTION}

Music listening is about understanding and enjoying the meanings and the aesthetics of music. It is an activity perceiving and understanding the characteristics and principles of the musical elements such as rhythm, melody, harmony, form, dynamics, tempo, and timbre. Moreover, music listening activities include the process of exploring the aesthetic elements in music through understanding of the contextual factors related to music (Boardman, 1996).

Recent technologies including digital media such as computers, iPods, and cellphones help us understand concepts and skills required for music listening, play, and creation. Various websites and online podcasts provide easy access and ample opportunities for students to stream and appreciate various genres and styles of music anytime, anywhere. A variety of mobile applications are special in that they are very popular with students nowadays and provide students with music understanding and skills in more individual environments (Bauer, 2014).

Much research has been performed on technologies as effective tools for facilitating learning in music; for example, Riley (2013) introduced the usage of tablet PCs, iPads and mobile device applications. He introduced seven types of applications which can be used in music education: rehearsal/performance assistance, creating music, teaching instruments, providing virtual instruments, audio/video recording, listening resources and organizational support. Williams (2014) suggested tablet PC's role as an instrument in music education. He mentioned that using iPads has a myriad of possibilities for ensemble performance and music learning. Rajan (2014) reviewed how children experience music through technology, and provided ideas for encouraging music listening, music making, and music watching at home and in the classroom. He further argued that parents as well as teachers should use such technologies in music education. Similarly, Heath-Reynolds \& VanWeelden (2015) introduced apps which can enhance music education and helped National Core Arts Standards (See http://www.nationalartsstandards.org/) introduce them into music class. They analyzed fifteen apps for creating music, six apps for performing, four apps for responding and two apps for connecting in order to suggest how apps can help music education. Dunbar 
(2016) presented the usefulness of seven free notation apps: Anyone Can Make Music, NotateMe Now!, Score Creator, Studiolab, Stave'n'Tabs, iWriteMusic, Melody Pro - specifically in creating music after analysis with rubrics of layout, intuitive, content accuracy, playback capabilities and export capabilities. Giebelhausen (2016) introduced paperless music class by providing a hybrid model of various hardware and software programs. Furthermore, he listed grants organizations and websites which can help establish such environments in schools.

In the same context of using technology in music education as with the above research and experience, this study aims to utilize an application and reveal its effectiveness in music listening. The primary objective of this study is to verify that three interactions through mobile applications can increase students' music listening. An auxiliary objective is to find any differences in satisfaction according to the three interactions through the mobile application.

\section{STRATEGIES FOR MUSIC LISTENING}

Recently, a variety of strategies have been tried to increase active and positive participation of students in music listening. In this effort, attention was suggested as one of the critical elements for meaningful music listening (Madsen \& Geringer, 2008). In order to enhance students' attention, research has been focused on adopting listening maps or verbal description as a learning activity in music (Cassidy, 2001; Flowers \& O'Neill, 2005; Gromko \& Russell, 2002; Johnson, 2011; Sims, 2005). Also research has been done on the collaborative music listening and interaction with others (Johnson, 2011; Smialek \& Boburka, 2006).

Johnson (2011) performed a study on the effects of critical thinking instruction on fifth-graders' music listening measured through written survey responses. This study suggested a constructivist approach to music listening instead of teacher-directed listening as a way to provide learning music. That is, this study tried to enhance students' thinking of musical context through analysis and exploration initiated by each student, as shown in Bamberger's study (2000). A contextual analysis of music was a main research topic of Walby (2011). He performed research on music terms acquired by analysis and comparison of music context among middle school students. This study suggested explanation and discussion in verbal form after having the students listen to the music. In this study, verbal communication was able to gain interest among the students, allowing them to form musical concepts consistent with fellow members of their musical culture. Talking about the music can also be a satisfying and culturally expected response to the concert experience.

The above studies suggest a proactive approach to music listening. Miller (1968) classified music listening into four types: passive listening by listening to music as is, sensory listening, with emotional listening to listen to music with its context and with bodily responses, and finally intellectual listening to listen to music with understanding and judgement about its structure and components. Later Wingell (1983) proceeded with the idea that people respond to music at first on a sensory level that prompts their senses, then on an associate level that relates to their previous experience and imagination, and finally on musical or formal level that analyzes the music in more detail. Hoffer (1988) classified music listening into three types. One way of listening to music is to absorb the physical sensations of the sounds. Enjoying music can be a pretty sensory, physical experience. The second way to listen to music is to be aware of its expressive qualities. The third way to listen to music involves concentrating on what is happening in the music - i.e., what notes are being played or sung, at what speed, in what range of pitches, in what combination with what other notes, and so on. Bauer (2014) admitted that people respond to music in various ways and that music educators should strive to develop students' abilities to listen to and describe music, analyze and evaluate it, understand its historical and cultural contexts, and appreciate its relationships to other disciplines, including other art forms.

From the preceding studies, three apparent ways of music listening could be extracted: One way is to appreciate music with senses as it is. Another way is to appreciate music with analysis of expressive characteristics, and the last way is to appreciate music with relation to its historical events, cultural context, and other genres of the arts. These three ways could be named sensory, analytic and aesthetic listening, respectively.

In this study, participants received one of the three strategies of music listening together with listening note embedded in the app. Table 1 shows three ways of music listening with their explanations and activities. 
Table 1. Three Ways of Music Listening, Definitions and Activities

\begin{tabular}{c|l|l}
\hline Ways of Listening & \multicolumn{1}{|c}{ Definition } & \multicolumn{1}{c}{ Activities } \\
\hline Sensory & $\begin{array}{l}\text { A strategy of music listening in } \\
\text { which people enjoy sensory } \\
\text { pleasure of music through its } \\
\text { flow and beauty. }\end{array}$ & $\begin{array}{l}\text { To express his or her own feelings in } \\
\text { words after listening to music and in } \\
\text { gestures when music is playing }\end{array}$ \\
\hline Analytic & $\begin{array}{l}\text { A strategy of music listening in } \\
\text { which people understand music } \\
\text { through analysis of its } \\
\text { components, such as rhythm, } \\
\text { tone, beat, melody, tempo, and } \\
\text { dynamic etc. }\end{array}$ & $\begin{array}{l}\text { To listen to music with understanding } \\
\text { of its thematic melody, its tempo and } \\
\text { tone, its repetition and changes, and its } \\
\text { tune. }\end{array}$ \\
\hline Aesthetic & $\begin{array}{l}\text { A strategy of music listening in } \\
\text { which people explore music with } \\
\text { its intrinsic and extrinsic } \\
\text { elements and evaluate its values. }\end{array}$ & $\begin{array}{l}\text { To understand the music's social and } \\
\text { cultural backgrounds. } \\
\text { To search its usage, role and values. } \\
\text { To evaluate the music itself and its } \\
\text { play. }\end{array}$ \\
\hline
\end{tabular}

\section{RESEARCH METHODS AND TOOLS}

\subsection{Participants}

A total of 225 students were purposely selected from a high school located in Daejeon, South Korea. All of them were in 10th grade and owned a smartphone. One hundred fourteen students were boy and one hundred eleven students were girls. Two classes were chosen at random and were allocated in each one of the three treatments: the interaction with peers, the interaction with teachers and the interaction with the application. The number of students in 'With Peers' treatment was 77, 'With Teachers' treatment had 72, and 'With the Application' had 76 students.

\subsection{Music Listening Test}

The music listening test was composed of three sections: analytic, aesthetic and sensory listening. The analytic section was comprised of six multiple choice items. The aesthetic section was comprised of three short essays and the sensory section of three short essays. All items were developed by researchers and revised three times by a music teacher who holds a master's degree in music education. The Cronbach Alpha for the analytic section was .91 and the test-retest reliability was .94 for this section. The aesthetic and sensory sections were graded by three music teachers with master's degrees in music education and the final scores were obtained by averaging the three scores. This test was utilized as pre and post-tests with random reordering.

\subsection{The Application}

The application used in the study was developed by Cho (2014). This application was designed for students' active music listening in that they can express their feelings by clicking 'Likes' as in Facebook. This application allows for students to listen to uploaded music and to write notes on analytic, aesthetic and sensory listening. Students can share their ideas by communicating with texts, attaching files and replying to peer posts.

A total of thirteen titles of music were uploaded to this application. They were selected by the researcher with the criteria of difficulty level and hierarchy of music learning. That is, in the analytic music listening, several elements are to be taken into account such as melody, sound level, tempo, dynamic, tone and beat. Not all music contains all these elements, but each title of music varies in their elements. The thirteen titles were ordered in sequence according to difficulty level. For example, the order of the music was arranged 
from the one with focus on tempo which might be easy for students to understand to the one focused on rhythm, beat, melody and dynamic in order. Each title was added to the preceding music's focused element. For aesthetic music listening, music was selected in consideration of their historical, cultural and social contexts. The information and explanation were attached to each music for better understanding of the music.

\subsection{Procedures and Data Gathering}

Before the listening started, the application was installed, and students were informed on how to use it. Twenty-six students, whose devices were not compatible with the application, were provided with smart phones with the application already installed. The participants were given one class hour of instruction on how to appreciate music, which included all three types of listening. They also had time to appreciate music, and practiced how to take a note in the application. Thus, all students became familiar with music listening with the app, taking notes and communicating with others.

A pretest was administered to all participants. This pretest was a music listening test before the assigned interaction for each group. For the treatment period, music was delivered each week, and the students were asked to write a listening note. Each preordered music was uploaded every Monday with its streaming video clip, tune, and its context information. They were also allowed to upload their own images together with text as a way of music listening note. The interaction group with the app listened to music provided on the app without any interaction with others, read the explanation and wrote a note. The interaction group with peers, after writing their notes, could open and comments on others' notes, share their opinions on the music. The interaction group with teachers could interact with teachers after writing their notes, asking questions regarding each topic. They could hear teachers' opinions on their notes. All interactions with peers and teachers were made through the comments menu in the application. A posttest was administered after about three months. This posttest was identical to the pretest, but the order of items was rearranged.

\section{RESULTS}

Before the treatment, homogeneity of the groups was tested for the three domains of music listening using ANOVA procedure in SPSS. As a result, the participants were homogeneous in music listening before the treatment regardless of the group to which they belonged. In order to test the effects of the three interactions, the ANCOVA procedure with pretest scores of music listening as covariates was applied for three domains of music listening: Analytic, Aesthetic and Sensory.

Below are the results of the ANCOVA in the order of Analytic, Aesthetic and Sensory. The interaction group with teachers shows the highest mean which is 9.20, the interaction group with peers shows the second highest mean with 8.54, and the interaction group with the application shows the lowest mean of 7.75. The whole participants' mean was 8.48. In order to test if these differences are statistically significant, the ANCOVA procedure was applied with the pretest score of analytic listening as a covariate. The result is presented in Table 1 below.

Table 2. ANCOVA for Between-Subjects Effects on Analytic Listening

\begin{tabular}{crrrc}
\hline Source & \multicolumn{1}{c}{ SS } & df & \multicolumn{1}{c}{ MS } & \multicolumn{1}{c}{ F } \\
\hline Corrected Model & $67.248^{\mathrm{a}}$ & 3 & 22.416 & $5.495^{* *}$ \\
Intercept & 399.734 & 1 & 399.734 & $97.984^{* *}$ \\
Pre_Analytic & 2.039 & 1 & 2.039 & .500 \\
Group & 63.769 & 2 & 31.885 & $7.816^{* *}$ \\
Error & 26.165 & 178 & 4.080 & \\
Total & 13875.000 & 182 & & \\
Corrected Total & 739.412 & 181 & & \\
\hline
\end{tabular}

$* * \mathrm{p}<.01$ 
According to Table 1 above, the differences were statistically significant. Therefore, the mean of the interaction group with teachers was highest, and that of the interaction group with peers was the second highest while that of the interaction group with the application was the lowest. To explore all possible pair-wise comparisons of means, the Least Significant Difference (LSD) procedure was applied. As a result, the biggest mean difference was found between the interaction with teachers and the interaction with the application, the difference of which was 1.438. The mean difference between the interaction with the application and the interaction with peers was also significant with a .802 difference. Meanwhile the difference between the interaction with peers and the interaction with teachers was not significant. Therefore, the interaction with teachers was most influential in analytic listening of the participants. The interaction with the application was least influential in analytic listening of the participants.

The same pattern of the analysis was applied to the case of aesthetic listening of the participants. The analysis shows that the interaction group with peers shows the highest mean which is 2.71 , the interaction group with teachers shows the second highest mean with 1.88 , and the interaction group with the application shows the lowest mean of 1.71. The whole participants' mean was 2.13. In order to test if these differences are statistically significant, the ANCOVA procedure was applied with the pretest score of aesthetic listening as a covariate. The results are presented in Table 2 below.

Table 3. ANCOVA for Between-Subjects Effects on Aesthetic Listening

\begin{tabular}{crrrr}
\hline Source & \multicolumn{1}{c}{ SS } & df & \multicolumn{1}{c}{ MS } & \multicolumn{1}{c}{ F } \\
\hline Corrected Model & $46.803^{\mathrm{a}}$ & 3 & 15.601 & $33.074^{* *}$ \\
Intercept & 62.989 & 1 & 62.989 & $133.538^{* *}$ \\
Pre_Analytic & 6.121 & 1 & 6.121 & $12.976^{* *}$ \\
Group & 38.454 & 2 & 19.227 & $40.762^{* *}$ \\
Error & 93.867 & 199 & .472 & \\
Total & 1060.000 & 203 & & \\
Corrected Total & 140.670 & 202 & & \\
\hline$* * p<.01$ & & &
\end{tabular}

According to Table 2 above, the differences were statistically significant. Therefore, the mean of the interaction group with peers was highest, and that of the interaction group with teachers was the second highest, while that of the interaction group with the application was the lowest. To explore all possible pair-wise comparisons of means, the Least Significant Difference (LSD) procedure was applied. As a result, the biggest mean difference was found between the interaction with the application and the interaction with peers, the difference of which was .975 . The mean difference between the interaction with peers and the interaction with teachers was also significant, with a .790 difference. Meanwhile the difference between the interaction with teachers and the interaction with the application was not significant. Therefore, the interaction with peers was most influential in aesthetic listening of the participants. The interaction with the application was least influential in analytic listening of the participants.

The same pattern of the analysis was applied to the case of sensory listening of the participants. According to the analysis, the interaction group with the application shows the highest mean, which is 2.64. The interaction group with peers shows the second highest mean with 1.47, and the interaction group with teachers shows the lowest mean of 1.34. The whole participants' mean was 1.83. In order to test if these differences are statistically significant, the ANCOVA procedure was applied with the pretest score of sensory listening as a covariate. The results are presented in Table 3 below.

Table 4. ANCOVA for Between-Subjects Effects on Sensory Listening

\begin{tabular}{crrrc}
\hline Source & \multicolumn{1}{c}{ SS } & df & \multicolumn{1}{c}{ MS } & \multicolumn{1}{c}{ F } \\
\hline Corrected Model & $76.115^{\mathrm{a}}$ & 3 & 25.372 & $53.027^{\text {** }}$ \\
Intercept & 304.996 & 1 & 304.996 & $637.446^{* *}$ \\
Pre_Analytic & 1.090 & 1 & 1.090 & 2.277 \\
Group & 75.634 & 2 & 37.817 & $79.038^{\text {** }}$ \\
Error & 101.913 & 213 & .478 & \\
Total & 908.000 & 217 & & \\
Corrected Total & 178.028 & 216 & & \\
$* * \mathrm{p}<.01$ & & &
\end{tabular}


According to Table 3 above, the differences were statistically significant. Therefore, the mean of the interaction group with the application was highest, and that of the interaction group with peers was the second highest while that of the interaction group with teachers was the lowest. To explore all possible pair-wise comparisons of means, the Least Significant Difference (LSD) procedure was applied. As a result, the biggest mean difference was found between the interaction with teachers and the interaction with the application, the difference of which was 1.302. The mean difference between the interaction with the application and the interaction with peers was also significant with a 1.185 difference. Meanwhile the difference between the interaction with peers and the interaction with teachers was not significant. Therefore, the interaction with the application was most influential in sensory listening of the participants. The interaction with teachers was least influential in analytic listening of the participants.

\section{DISCUSSION, CONCLUSION AND SUGGESTIONS}

The interaction with teachers was most influential in the analytic listening of the participants. The interaction with the app was least influential in the analytic listening of the participants. The analytic listening is to understand and differentiate the expressive elements of music while listening to music. One of the results of this study, the interaction with teachers was most influential in the analytic listening of the participants, could be due to the instructors' input. On the other hand, the fact that interaction with the application was least influential in the analytic listening of the participants may be attributable to the non-existence of any help from others in acquiring skills and methods for understanding and differentiating these elements of the music. The interaction with peers was most influential in aesthetic listening of the participants. The interaction with the application was least influential in aesthetic listening of the participants.

The aesthetic listening is to locate overt and covert expressive beauty of music and evaluate its value in the context of the society and culture in which the music was created. This listening accompanies understanding of the music's characteristics, of related stories and of reflections of them into the music. The participants interacting with peers could communicate all of their comments with others. Because the aesthetic listening is more closely related to the contextual knowledge of the music, participants interacting with peers could enhance their aesthetic listening and their contextual knowledge by reading others' notes and sharing comments. The lowest aesthetic listening of the participants interacting with the application is attributable to the same reason stated above.

The interaction with the application was most influential in sensory listening of the participants. The interaction with teachers was least influential in sensory listening of the participants. The sensory listening is to express listener's feelings into words, images, or bodily gestures while listening to music. That is, the sensory listening does not accompany any other kinds of deep thinking or understanding; rather the listeners use their senses to appreciate the music with ease and comfort. In this study, participants interacting with the application listened to the music with the explanation and read how to appreciate the music with no interaction with others. The fact that participants interacting with the application showed higher sensory listening could be due to the fact that they could react to the music with their ease and freedom without others' intervention or control. The other participants interacting with teachers and peers could be distracted during sensory listening in search of analyzing and evaluating the music's context and elements.

The interaction group with the application was most satisfied with music listening. The interaction group with peers was least satisfied with music listening. This may be due to the fact that they feel more freedom without the need to pay attention to others. On the other hand, the participants interacting with peers showed the lowest satisfaction. This might be due to the fact that they had to pay more attention to others' postings and they had written their notes in the application. This should have doubled their work load and they might feel stress.

Implications of this study are that analytic listening can be effective through the interaction with experts, aesthetic listening could be enhanced with interactions with peers and sensory listening could be enhanced with interactions with the application. These results imply that analytic listening needs to be focused on a coaching method involving experts' guidance, aesthetic listening needs to be focused on a discussion with peers and sensory listening needs to be focused on more free and comfortable listening environments. 


\section{REFERENCES}

Bauer, W. I., 2014. Music Learning Today. New York: Oxford University Press.

Bamberger, J. (2000). Developing musical intuitions. New York, New York: Oxford University Press.

Boardman, E., 1996. Toward a theory of music instruction: A generative approach to music learning. Unpublished instructional material, Urbana: University of Illinois

Cassidy, J. W. (2001). Listening maps: Undergraduate students; ability to interpret various iconic representations. Update: Applications of Research in Music Education, 19(2), 15-19.

Cho, S. K., 2014. Design and Implementation of Smart Learning System for Music Appreciation. Journal of Music Education Science. Vol. 18, pp. 231-249.

Dunbar, L. (2016). Free Notation Apps: What Is Out There? General Music Today, 29, 39-44.

Flowers, P. J., \& O’Neill, A. A. (2005). Self-Reported Distractions of Middle School Students in Listening to Music and Prose. Journal of Research in Music Education, 53, 308-321.

Giebelhausen, R., 2016. The Paperless Music Classroom. General Music Today, Vol. 29, pp. 45-49.

Gromko, J. E., \& Russell, C. (2002). Relationships among young children's aural perception, listening condition, and accurate reading of graphic listening maps. Journal of Research in Music Education, 50, 333-342.

Heath-Reynolds. J., \& VanWeelden, K. (2015). Integrating Apps with the Core Arts Standards in the 21st-Century Elementary Music Classroom. General Music Today, 29, 24-27.

Hoffer, C. R. (1988). A Concise Introduction to Music Listening (4th ed.) Belmont, Calif.: Wadsworth Pub. Co.

Johnson, E. (2011). Developing Listening Skills through Peer Interaction. Music Educators Journal, 98(2), 49-54.

Johnson, D. C. (2011). The Effect of Critical Thinking Instruction on Verbal Descriptions of Music. Journal of Research in Music Education, 59, 257-272.

Madsen, C. K., \& Geringer, J. M. (2008). Reflections on Puccini's La Boheme: Investigating a Model for Listening. Journal of Research in Music Education, 56, 33-42.

Miller, H. M. (1968). Introduction to music: a guide to good listening. New York; Barnes \& Noble.

Rajan, R. S., 2014. Tapping into Technology: Experiencing Music in a Child's Digital World. General Music Today, Vol. 28, No. 1, pp. 8-11. doi:10.1177/1048371314544169

Riley, P., 2013. Teaching, Learning, and Living with iPads. Music Educators Journal, Vol. 100, pp. 81-86.

Sims, W. L. (2005). Effects of free versus directed listening on duration of individual music listening by prekindergarten children. Journal of Research in Music Education, 53, 78-86.

Smialek, T. W., \& Boburka, R. R. (2006). The effect of cooperative listening exercises on the critical listening skills of college music appreciation students. Journal of Research in Music Education, 54, 57-72. doi:10.2307/3653455

Walby, N. (2011). Tell Me What You Hear: Vocabulary Acquisition and Application in the General Music Middle School Classroom. Music Educators Journal, 98, 55-60. doi: 10.1177/0027432111426784

Williams. D. A., 2014. Another Perspective: The iPad Is a REAL Musical Instrument. Music Educators Journal, Vol. 101, pp. 93-98.

Wingell, R. (1983). Experiencing Music. Sherman Oaks, Calif.: Alfred Pub. Co. 